\title{
Diversidade populacional de Colletotrichum sublineolum em seis localidades no Brasil*
}

\author{
Dagma Dionísia da Silva1,3 ${ }^{1,3}$ Carlos R oberto Casela², Hilário A ntônio de Castro ${ }^{1}$, F redolino Giacomini dos Santos ${ }^{2}$, \\ Alexandre da Silva Ferreira ${ }^{2}$
}

\begin{abstract}
${ }^{1}$ U niversidade F ederal de L avras, D epartamento de Fitopatologia, 37200-000, L avras-M G; ${ }^{2}$ E mbrapa M ilho e Sorgo, Sete L agoas, M G. ${ }^{3 B}$ olsista do CN Pq. *Parte da dissertação de mestrado do primeiro autor.

A utor para correspondência: Hilário A ntonio de Castro

Data de chegada: 04/04/2007. A ceito para publicação em: 19/11/2007
\end{abstract}

1466

\section{RESUMO}

Silva, D.D., Casela, C.R.; Castro, H.A.; Santos, F.G., Ferreira, A.S. Diversidade populacional de Colletotrichum sublineolum, em seis localidades no Brasil. Summa Phytopathologica, v.34, n.2, p.149-155, 2008

Foi objetivo deste trabalho caracterizar a população de Colletotrichum sublineolum Henn. por meio da avaliação da virulência de 289 isolados monospóricos do patógeno. Foram utilizadas como diferenciadoras 10 linhagens elites do programa de melhoramento genético de sorgo da Embrapa Milho e Sorgo. Os isolados de C. sublineolum foram obtidos de folhas de sorgo provenientes de Palmeira de Goiás e Goiânia, GO, Sete Lagoas, I piaçu e Uberlândia, M G, e Jardinópolis, SP e designados de acordo com um sistema binário de classificação de raças. As populações foram também caracterizadas quanto à diversidade fenotípica, por meio de índices de Shannon, de Gleason e de Simpson, e de um índice de complexidade, e quanto a sua distribuição e freqüência nas seis localidades. Somente a raça 31.04 foi encontrada nos seis locais avaliados e foi a raça mais freqüente em Uberlândia, I piaçu e Palmeira de Goiás. A raça mais complexa, 31.31, foi a mais freqüente em Sete Lagoas e Goiânia e não foi observada somente em Palmeira de Goiás. Verificou-se que as raças mais freqüentes em cada localidade apresentaram-se, em sua maioria, bem distribuídas nas seis regiões avaliadas. 0 local com maior diversidade fenotípica foi Jardinópolis, de acordo com os índices de Shannon, Simpson e Gleason. 0 maior índice de complexidade de raças foi encontrado em Sete Lagoas e Goiânia, seguidas por Jardinópolis, Ipiaçu, Uberlândia e Palmeira de Goiás, respectivamente. Houve correlação entre os índices de Shannon e Gleason, mas não entre os índices de diversidade e de complexidade.

Palavras-chave adicionais: Sorghum bicolor, Diversidade fenotípica, Complexidade de raças.

ABSTRACT

Silva, D.D., Santos, F.G., Ferreira, A.S., Castro, H.A., Casela, C. R. Population diversity of Colletotrichum sublineolum, in six locations in B razil. Summa Phytopathologica, v.34, n.2, p.149-155, 2008

The objective of this work was to characterize Colletotrichum sublineolum Henn. population by evaluating virulence of 289 single spore isolates of the pathogen in sorghum 10 elite lines of the breeding program of Embrapa Maize and Sorghum Research Center, utilized as differentials. Isolates were obtained of sorghum leaves from Palmeira de Goiás and Goiânia, GO, Sete Lagoas, I piaçu and U berlândia, M G, and Jardinópolis, SP and designated according to a binary system of classification. Populations were also characterized for phenotypic diversity according to the Shannon, Gleason and Simpson indexes, a complexity index, and according to their frequency and distribution. Race 31.04 was present in all six locations and was the predominant phenotype in U berlândia, I piaçú, and Palmeira de Goiás. The complex race 31.31, was the most frequent in Sete Lagoas and Goiânia and was not observed only in Palmeira de Goiás. The most frequent races were also the ones with a uniform distribution throughout the six locations. The highest phenotypic diversity, according to the Shannon, Simpson and Gleason indexes, was observed in J ardinópolis. The highest complexity index was found in Sete Lagoas and Goiânia, followed by the indexes of Jardinópolis, I piaçu, U berlândia and Palmeira de Goiás, respectively. A significant correlation between Shannon and Gleason indexes was observed. On the other hand, diversity and complexity indexes were not significantly correlated.

Additonal K eywords: Sorghum bicolor, Shannon, Simpson, Gleason and Complexity indexes.

A antracnose do sorgo é a principal e mais devastadora doença que ameaça a produção dessa cultura no Brasil. Ela reduz a produção no campo e é favorecida por condições de umidade e temperaturas al tas, podendo provocar perdas severas, mesmo em regiões com breves períodos de chuva, seguidos de seca prolongada. A doença tem Colletotrichum sublineolum como agente etiológico. Este fungo infecta todas as partes da planta, porém, a fase foliar da doença é a mais importante, por reduzir a produção de grãos e de forragem em $50 \%$ ou mais, dependendo da severidade da epidemia $(7,10,16,18)$.

A variabilidade em $C$. sublineolum é al ta e foi inicialmente demonstrada por Harris \& J ohnson (14), quando observaram variações no grau de resistência entre genótipos de sorgo, que foram atribuídas 
à existência de raças fisiológicas na população do patógeno.

V ários outros trabal hos já demonstraram a capacidade adaptativa do patógeno a cultivares geneticamente resistentes, o que diminui a vida útil de híbridos comerciais, resultando em grande prejuízo para produtores e exigindo maiores esf orços de melhoristas e fitopatologistas na busca de soluções para o controle desta doença. Para o controle da antracnose do feijão que tem como agente etiológico, Colletotrichum lindemuthianum (Sacc. e M agn.) Scrib., patógeno também de alta variabilidade, nove cultivares de feijão tipo carioca são usadas como fonte de resistência a todas as raças de $C$. Iindemuthianum, U romyces appendiculatus e $P$ haeoisariopsis griseola (Sacc.), (exceto raça 63.63) $(2,18)$. Isto é possível devido ao acompanhamento do surgimento de novas raças no Brasil, o que também deve ser feito para a cultura do sorgo com objetivo de aumentar a durabilidade da resistência à antracnose e escolher estratégias de controle eficientes.

A caracterização da estrutura das diferentes populações do patógeno é uma etapa imprescindível, para qualquer trabalho de melhoramento que tenha por objetivo a resistência à antracnose do sorgo. Conhecendo-se a estrutura de virulência, a diversidade fenotípica, a complexidade e a distribuição de raças por região, é possível estabelecer estratégias que limitem a capacidade adaptativa do patógeno e, com isso, diminuir as perdas causadas pela doença.

Foi objetivo deste trabalho caracterizar a população de $C$. sublineolum por meio da avaliação da virulência em linhagens elites de sorgo, do programa de melhoramento genético da Embrapa M ilho e Sorgo, utilizadas como diferenciadoras.

\section{MATERIAL E MÉTODOS}

0 trabalho foi conduzido utilizando-se a infra-estrutura do L aboratório de R esistência de Plantas a Doenças e casas-de-vegetação da Embrapa M ilho e Sorgo, no período de julho de 2004 a dezembro de 2005.

F oram aval iadas 10 linhagens elites do programa de mel horamento genético de sorgo da E mbrapa M ilho eSorgo, as quais foram inoculadas com 289 isolados monospóricos do patógeno, obtidos nas local idades de Sete L agoas, U berlândia e I piaçu, M G, Goiânia e Pal meira de Goiás, GO, e Jardinópolis, SP (Tabela 1).

O btenção dos isolados de Colletotrichum sublineolum

Fragmentos de folhas de sorgo com sintomas da doença foram desinfestados superficialmente por dois a três minutos em solução de hipoclorito de sódio a 0,5\% e plaqueados em meio de farinha de aveiaagar (FAA ). A s placas foram, em seguida, incubadas sob luz fluorescente contínua à temperatura de $25{ }^{\circ} \mathrm{C}$ por sete a oito dias. Seguiu-se uma raspagem superficial para a eliminação do crescimento micelial da colônia, cinco dias após o isolamento, para a indução de esporulação. Sete dias após, os conídios foram coletados por meio do corte de fragmentos do meio de cultura e transferidos para tubos de ensaio contendo $9 \mathrm{~mL}$ de água destilada e esterilizada, seguindo-se uma diluição em série até $10^{-4}$. Em seguida, $1 \mathrm{~mL}$ da suspensão obtida foi distribuído em 3 placas de Petri contendo agar-água ( $A$ A ) a $2 \%$, as quais foram incubadas a $25^{\circ} \mathrm{C}$, por 12 horas, para a indução de germinação. Culturas monospóricas foram, então, obtidas por meio da coleta de um conídio ao microscópio de luz. 0 conídio foi coletado pelo corte de um fragmento correspondente ao foco de luz do microscópio. Os isolados, depois de transferidos para tubos de ensaio contendo FAA, foram incubados sob luz contínua por aproximadamente sete dias, quando adicionou-se óleo mineral para conservação dos mesmos até o momento de uso.

Foram obtidos 289 isolados monospóricos, sendo 50 de Sete Lagoas, 50 de Uberlândia, 54 de Ipiaçu, 47 de Goiânia, 69 de J ardinópolis e 19 de Palmeira de Goiás. A s amostras de Sete L agoas, Goiânia, U berlândia e Palmeira de Goiás foram coletadas em 2004, a amostra de J ardinópolis foi coletada parte em 2004 e parte em 2005, e somente I piaçu teve toda sua amostragem coletada no ano de 2005. D eve-se ressaltar que a amostragem em Pal meira de Goiás foi composta por apenas 19 isolados, devido a um período de seca no ano de 2005, que impediu que nova amostragem fosse realizada.

Produção de inóculo e inoculação de Colletotrichum sublineolum

Os isolados monospóricos de C. sublineolum foram transferidos do óleo mineral para placas de Petri com meio FA A e mantidos sob luz fluorescente contínua por sete a oito dias. Para indução de esporulação, realizou-se raspagem superficial aos 5 dias de crescimento e, após cinco a seis dias, os isolados foram repicados para novas placas contendo FA A . 0 mesmo procedimento para a indução da esporulação necessária para o preparo de inóculo foi adotado para as placas contendo o fungo em crescimento. Cinco dias depois, às placas de cada isolado foi adicionado aproximadamente $5 \mathrm{~mL}$ de água destilada, seguindo-se uma raspagem superficial com uma espátula para a liberação de conídios e posterior contagem em câmara de Neubauer. A concentração de inóculo utilizada foi de $10^{6}$ conídios $/ \mathrm{mL}$.

A s plantas das 10 linhagens de sorgo foram inoculadas aos 28 dias após a semeadura, com a suspensão de esporos do patógeno na proporção de $10 \mathrm{~mL} / v a s o$. A pós a inoculação, as plantas foram mantidas em câmara úmida por 18 horas, à temperatura média de $25^{\circ} \mathrm{C}$. Os tratamentos foram dispostos em parcelas subdivididas, com os isolados nas parcelas e os cultivares nas subparcelas, com 3 repetições. Um vaso de $5 \mathrm{~kg}$ com cinco a seis plantas caracterizou uma repetição.

Tabela 1: Linhagens de sorgo utilizadas como diferenciadoras e sua numeração para nomeação de raças de C. sublineolum para a caracterização de populações do patógeno. UFLA. Lavras-M G, 2006.

Numeração binomial da linhagem Linhagens restauradoras ${ }^{1} \quad$ Numeração binomial da linhagem Linhagens macho-estéreis ${ }^{2}$

$\begin{array}{cccc}1 & \text { BR } 009^{3} & 1 & \text { ATF8A } \\ 2 & \text { BR 012R } & 2 & \text { ATF 14A } \\ 4 & \text { CMSXS180R } & 4 & \text { ATF54A } \\ 8 & \text { CMSXS182R } & 8 & \text { CMSXS206A } \\ 16 & 9910032 & 16 & 9409131\end{array}$

${ }^{1}$ A s linhagens restauradoras correspondem aos machos.

${ }^{2} \mathrm{As}$ linhagens macho-estéreis correspondem às fêmeas e foram utilizadas as mantenedoras B nos experimentos.

${ }^{3}$ L inhagem padrão de suscetibilidade. 
Tabela 2: Distribuição e freqüência das principais raças de C. sublineolum em seis localidades no Brasil, entre um total de 70 raças identificadas. UFLA. Lavras - M G, 2006.

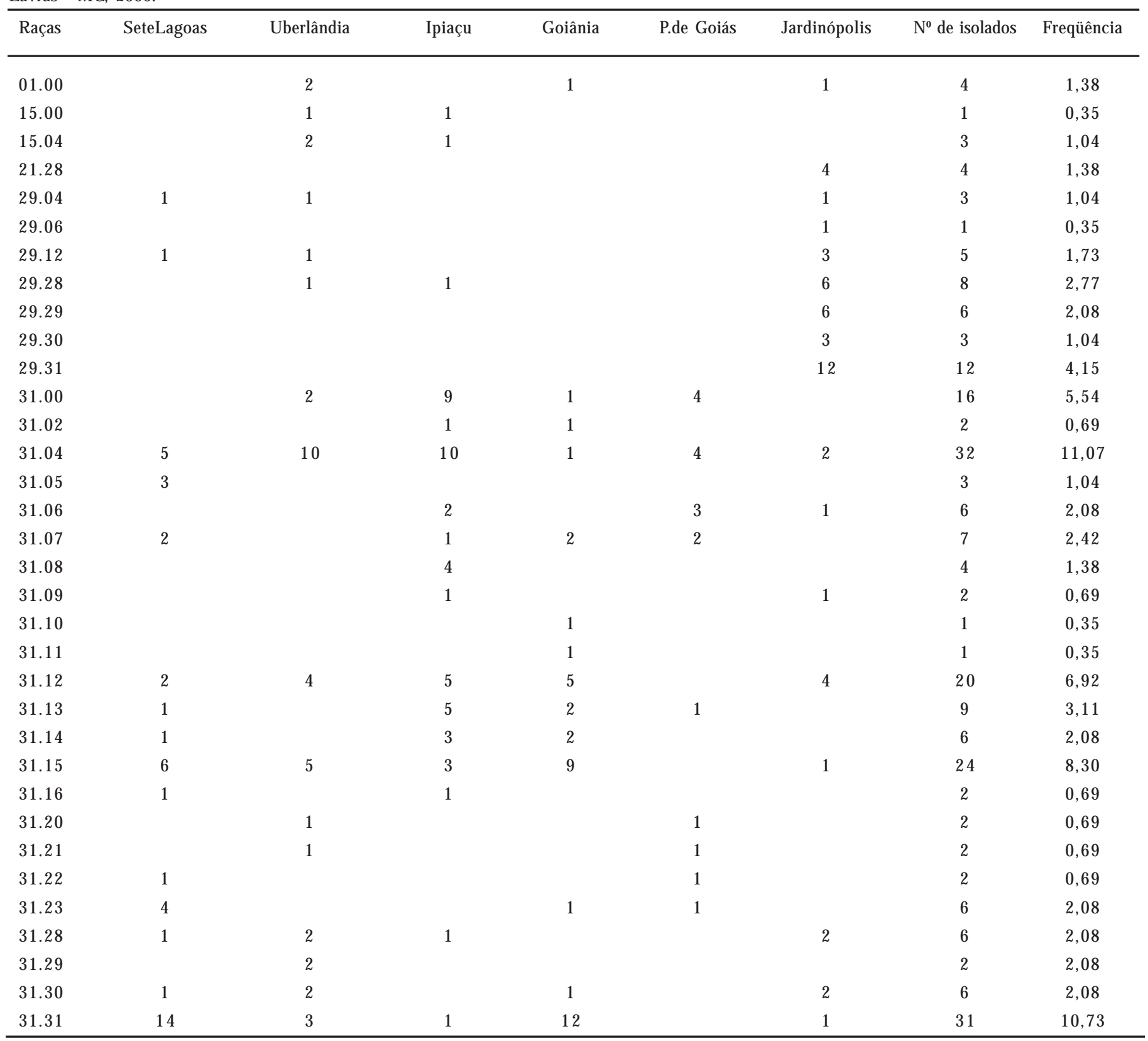

Avaliação

A reação dos genótipos foi avaliada aos 12 dias após a inoculação, utilizando-se uma escala de notas com valores de 1 a 5 , conforme Cardwel et al. (5), em que: 1 - presença de pequenas pontuações necróticas, 2 - presença de pequenas manchas avermelhadas, 3 - lesões necróticas, algumas vezes alongadas, mas sem a presença de esporulação, 4 - lesões necróticas com a presença de acérvulos no centro e 5 - lesões necróticas, al gumas vezes coalescidas, com a presença de abundante esporulação. D uas classes de reação foram consideradas: $\mathrm{R}=$ reação de resistência (incluindo as notas 1 , 2 e 3 ) e $S=$ reação de suscetibilidade (notas 4 e 5). Raças do patógeno foram designadas por sistema binário segundo metodologia utilizada por N ietsche et al. (18), em que cada linhagem restauradora e cada macho-estéril recebeu uma numeração de 1 a 16 (Tabela 1). A raça foi nomeada somando-se a numeração de cada linhagem restauradora suscetível a um mesmo isolado e também cada linhagem macho-estéril, respectivamente.

A diversidade fenotípica de cada subpopulação foi calculada por meio dos índices de Shannon, de Simpson e de Gleason, conforme Groth \& Roelfs (13) ea complexidade segundoA ndrivon \& VallavieillePope (1). Os índices de diversidade fenotípica seguem as fórmulas:

Shannon: $\mathrm{Sh}=$ - S pi In (pi), em que: pi éa freqüência da raça i na população.

Simpson: Si = S [ni (ni -1)/ N (N-1)] em que: ni é o número de isolados pertencentes à raça i e $\mathrm{N}$ é 0 tamanho da amostra.

Gleason: $G \mid=(r-1) / \ln (N)$, em que: $r$ é o número de fenótipos distintos na amostra e $\mathrm{N}$ é o número de indivíduos na amostra.

0 índice de complexidade é baseado na freqüência relativa do fenótipo na amostra e o seu número de virulências foi calculado pela fórmula: $\mathrm{Ci}$ = S (pi .vi) em que: pi é a freqüência da raça na amostra e vi é o número de virulências da raça. Considera-se o número de 
virulências da raça como o número de genótipos do hospedeiro com reação de suscetibilidade a esta, ou seja, o número de genótipos para os quais o isolado é virulento.

R eal izou-se a análise de correlação simples e aplicação do testeT, a $5 \%$ e $1 \%$ de probabilidade, entre índices de diversidade e entre estes e o índice de compl exidade. U tilizou-se o programa estatístico A ssistat, desenvolvido por Souza e Silva (21).

As raças foram analisadas também quanto a sua distribuição, freqüência e virulência nos locais de amostragem do patógeno. A porcentagem de virulência foi cal culada pela distribuição em faixas de um a três, quatro a seis e sete a dez virulências e dividindo-se o total de raças, dentro de cada faixa, pelo número total de raças identificadas nas seis populações.

\section{RESULTADOS E DISCUSSÃO}

Foram encontradas 70 raças de C. sublineolum nos 289 isolados monospóricos testados nas 10 linhagens diferenciadoras, tendo sido identificadas 21 raças em Sete L agoas, 24 em U berlândia 20 em I piaçu, 18 em Goiânia, 10 em Palmeira de Goiás e 32 em Jardinópolis.

Do total de 70 raças, 46 foram encontradas somente em uma Iocali dade e apenas a raça 31.04 esteve presente em todas as local idades. A s raças mais freqüentes do total de isolados testados foram: 31.04

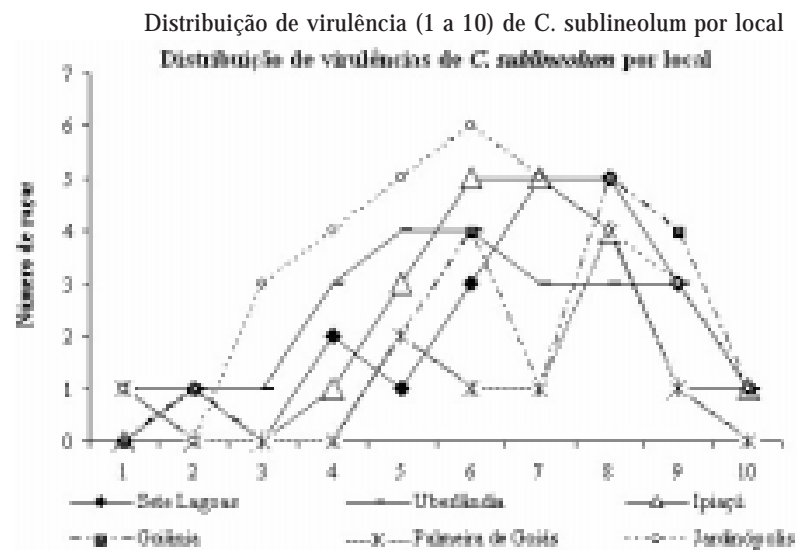

Figura 1: Distribuição do número de virulências de Colletotrichum sublineolum em seis regiões de cultivo de sorgo no Brasil. UFLA. Lavras M G, 2006.
$(11,07 \%), 31.31(10,73 \%), 31.15(8,30 \%), 31.12(6,92 \%), 31.00$ $(5,54 \%)$ e $29.31(4,15 \%)$ (Tabela 2$)$.

A raça mais complexa detectada foi a 31.31 , composta por $10,73 \%$ dos isolados, virulenta a todas as linhagens diferenciadoras e encontrada em Sete L agoas, U berlândia, I piaçu, G oiânia e J ardinópolis. E sta raça apresentou a maior freqüência em Sete L agoas e G oiânia, envolvendo $28,00 \%$ e $25,53 \%$ do total de isolados testados em cada localidade, respectivamente. Nas outras localidades, essa raça apresentou baixa freqüência (Tabela 2).

A raça 31.04 , que foi a única encontrada em todos os locais estudados, foi a mais freqüente em U berlândia (20\%), I piaçu (18,52\%) e Palmeira de G oiás (21,05\% ). Em Sete L agoas, esta raça apresentou a terceira maior freqüência e em G oiânia e J ardinópolis, sua freqüência foi baixa.

A raça 31.15 apresentou a segunda maior freqüência em Sete L agoas, U berlândia e Goiânia, e apenas em Palmeira de G oiás sua presença não foi detectada. A raça 31.12 também não foi detectada em Palmeira de Goiás e apresentou a tercei ra maior freqüência em U berlândia, I piaçu Goiânia e Jardinópolis (Tabela 2). Em Jardinópolis, a raça mais freqüente foi a 29.31, correspondendo a $17,39 \%$ dos 69 isolados desse local, seguida pelas raças 29.29 e 29.28 , ambas com freqüência de $8,70 \%$.

O bservou-se, pela distribuição das raças em cada local idade e pelas faixas de virulência, que aquelas com número de virulência intermediário e amplo prevaleceram em relação às de menor virulência (Figura 1).

A maior diversidade fenotípica, de acordo com os índices de Shannon, de Simpson e de Gleason, foi encontrada em J ardinópolis, SP, com valores de 3,114; 0,949 e 7,321, respectivamente. U berlândia foi o segundo local com a maior diversidade, com valores de 2,814; 0,940 e 5,624, para os índices de Shannon, Simpson e Gleason, respectivamente (Figura 2). Em Sete L agoas, I piaçu, Goiânia e Palmeira de Goiás, a diversidade medida pelos índices apresentou variação de local para local, demonstrando que as populações de Sete L agoas e de G oiânia possuem um menor número de fenótipos distintos e al gumas raças dominantes na população em relação às outras. E $m$ U berlândia e I piaçu, há um menor número de fenótipos distintos na amostra, que estão mais uniformes quanto à freqüência na população. Palmeira de Goiás possui um pequeno número de fenótipos distintos, mas com al gumas raças dominantes na população. Em J ardinópolis observouse um grande número de fenótipos distintos, segundo o índice de

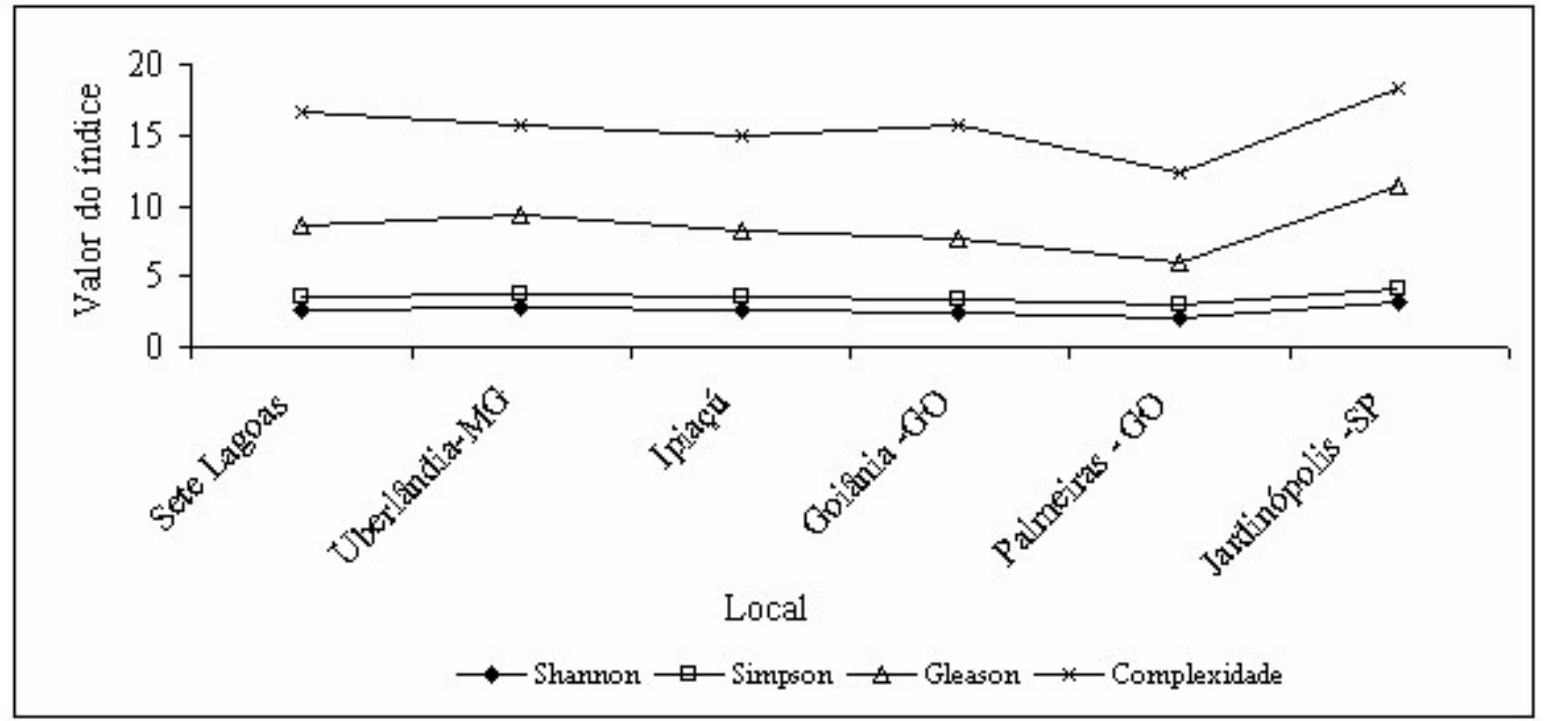

Figura 2: Índices de diversidade e de complexidade de Colletotrichum sublineolum em seis regiões de cultivo de sorgo no B rasil. UFLA. Lavras - M G, 2006. 
Gleason, mas com maior dominância de al gumas raças sobre as outras, com base nos índices de Shannon e Simpson.

Com relação à complexidade das raças identificadas, Sete $L$ agoas e Goiânia foram os locais com maior predominância de raças de al ta complexidade, embora não apresentassem alta diversidade, conforme expresso pelos valores de Shannon, de Simpson e de Gleason (Figura 2).

Índices de diversidade são usados para descrever a diversidade intra-específica de raças em populações de diversos patógenos. Os índices de Shannon e Simpson são baseados na freqüência relativa dos diferentes fenótipos do patógeno e medem o número de fenótipos distintos na amostra e a uniformidade da sua distribuição.

Para se comparar duas populações de tamanho variável, e que aparentemente não diferem entre si quanto ao grau de dominância dos fenótipos ou quanto ao número de fenótipos, o índice de Shannon pode ser a melhor escolha. Porém, se o interesse é verificar primeiramente o grau de dominância de determinadas raças na população, recomenda-se usar o índice de Simpson, que é mais sensível que o índice de Shannon, embora ambos sejam aceitáveis. Já o índice de Gleason se baseia apenas no número de fenóti pos diferentes obtidos, em relação a um determinado número de isolados $(13,15)$.

Considerando-se que o índice de G leason informa sobre o número de fenótipos distintos na amostra, mas, não possibilita definir se essa população tem uma distribuição mais uniforme quanto à freqüência das raças, como podem informar os índices de Shannon e Simpson, e, ainda, o fato do índice de Shannon sofrer menor influência da variação no tamanho da amostra que os outros dois, faz com que este seja recomendado em trabal hos nos quais esta variação ocorre.

0 índice de Simpson pode informar mais claramente sobre a predominância de algumas raças na população ou se as raças estão bem distribuídas. Se o valor estiver próximo de 0, a mai oria das raças está em baixa freqüência na população e um valor mais próximo de 1 indica que al gumas raças aparecem em maior freqüência na população em relação à maioria identificada.

A utilização de mais de um índice de diversidade para a caracterização da população do patógeno é, portanto, recomendável, visto que cada um responde mais sensivelmente a determinada característica da população.

0 índice de complexidade, que se baseia na freqüência relativa e número de virulência de determinada amostra, possibilita analisar a população quanto à adaptação aos genótipos da cultura em diferentes regiões de plantio.

$\mathrm{N}$ ão houve correlação entre os índices de diversidade e o de complexidade, mas observou-se uma correlação positiva entre os índices de Shannon e Gleason a 1\% de probabilidade. A s demais correlações entre os índices de diversidade, apesar de positivas, não foram significativas (Tabela 3).

Estes resul tados mostraram a existência de diferenças na estrutura populacional do patógeno em cada localidade. A melhor caracterização da população poderia ser al cançada se a amostragem fosse realizada em épocas diferentes durante o ciclo da cultura, e se a variação no tamanho das amostras fosse a menor possível. Esta medida deve ser tomada para que a diversidade não sofra influência da variação no tamanho da população entre localidades.

R esultado semel hante em relação ao número de raças identificadas neste trabal ho foi obtido por Casela et al. (11), quando avaliaram 314 isolados monospóricos do patógeno, coletados em Sete L agoas, M G, Cravinhos, SP e Pelotas, RS, nos anos de 1999 e 2000, e encontraram 75 fenótipos diferentes. Os autores verificaram que 16 fenótipos ocorreram nos dois anos de coleta e que somente seis raças incluíram $68 \%$ do total de isolados testados, ou seja, prevaleceram na população do patógeno e quatro foram detectados em todos os locais. No presente trabalho, também, seis isolados foram mais comuns, porém a porcentagem destes sobre o total de isolados correspondeu a 46,71\%, valor 21,29\% menor que o apresentado pelos citados autores.

Em contraste com o trabal ho anteriormente citado, em que 4 raças apareceram em todos os locais, neste, somente a raça 31.04 ocorreu em todas as localidades. Porém, este resultado pode ser devido à pequena amostragem de Palmeira de Goiás, que pode ter limitado a detecção real dos fenótipos presentes no local. Um aumento na proporção do fenótipo mais comum também foi verificado em comparação com o fenótipo mais comum do trabal ho anterior que foi $9,55 \%$ do total de isolados, enquanto que, neste trabal ho, a porcentagem foi de $11,07 \%$, sugerindo que este fenótipo está bem adaptado à população do patógeno. Tais diferenças podem também ter sido determinadas pelo fato de que Casela et al. (11) utilizaram outras diferenciadoras que as utilizadas neste trabalho.

A s variações na diversidade observada podem representar uma resposta do patógeno à população do hospedeiro em cada local e a uma especial ização das raças nas áreas avaliadas. E m J ardinópolis, os isolados do patógeno foram coletados dentro da área experimental da empresa D ow A grosciences, em genótipos de sorgo da empresa e os isolados certamente refletiram a diferença da base genética dos genóti pos do hospedeiro da Dow e da Embrapa. É provável, que se fossem utilizados genótipos da Dow para a caracterização da população, poderia haver uma maior compl exidade e uma menor diversidade, pois, neste local, prevaleceriam as raças mais adaptadas aos genes de resistência dos genótipos desta empresa. Em U berlândia, I piaçu e Palmeira de Goiás, os isolados foram amostrados em material da Embrapa, mas, em genótipos diferentes dos utilizados neste trabal ho, o que também explica a variação entre a diversidade entre locais.

Quanto ao índice de complexidade, os resultados sugerem que,

Tabela 3: Correlação linear simples entre Índices de diversidade e complexidade. UFLA . Lavras - M G, 2006.

\begin{tabular}{ccc}
\hline Correlação & Coeficiente de correlação $(r)$ & Significância \\
\hline Complexidade $\times$ Shannon & -0.07 & $\mathrm{~ns}$ \\
Complexidade $\times$ Simpson & -0.65 & $\mathrm{~ns}$ \\
Complexidade $\times$ Gleason & 0.05 & $\mathrm{~ns}$ \\
Shannon $\times$ Simpson & 0.78 & $\mathrm{~ns}$ \\
Shannon $\times$ Gleason & 0.98 & $* *$ \\
Simpson $\times$ Gleason & 0.72 & $\mathrm{~ns}$ \\
\hline
\end{tabular}

** significativo pelo teste $\mathrm{T}$ a $1 \%$ de probabilidade, ns = não significativo. 
pelo menos em Sete L agoas, raças mais complexas preval eceram e que este alto índice pode ser resultado da resposta do patógeno a uma maior diversidade genética do hospedeiro, dado o grande número de genótipos de sorgo presentes a cada ano na área experimental da E mbrapa M ilho e Sorgo. Provavelmente, essa al ta diversi dade genética no hospedeiro fez com que esses genes para virulência se tornassem necessários na população do patógeno e a seleção direcional estaria atuando de maneira a preservá-los. Esta seria uma vantagem para 0 patógeno, pois estes genes acabariam se fixando na população em substituição às raças menos complexas, o que explica a menor diversidade neste local e em G oiânia, onde os genótipos testados são oriundos de Sete L agoas. N este caso, é possível que a seleção direcional esteja atuando em favor de raças mais complexas, portanto, mais adaptadas às linhagens resistentes. Para as outras localidades, onde houve pouca diferença entre os val ores dos índices de complexidade, a sel eção estabilizadora pode estar atuando com mais força. A lém disso, a diversidade genética do hospedeiro provavel mente é menor.

U ma outra provável explicação para a adaptação das raças mais complexas é que, na ausência de recombinação genética em $C$. sublineolum, que éum patógeno de reprodução basicamente assexuada, um gene de virulência desnecessário pode ter sua proporção aumentada na população do patógeno, por estar ligado a outro gene de virulência sob pressão de seleção ou estar associado a genes responsáveis por maior agressividade, ou seja, os efeitos deletérios resultantes da virulência desnecessária podem ser anulados pela ação da seleção sobre combinações favoráveis de genes para sobrevivência $(3,7,22)$. De acordo com Brown (4), a adaptação do patógeno à resistência do hospedeiro pode resultar da rápida multiplicação de um único indivíduo com os fatores de virulência correspondentes ou de uma série de indivíduos geneticamente distintos, tendo em comum os referidos genes de virulência. Casela (6) verificou al ta variabilidade apresentada por C. sublineolum em avaliação de isolados monospóricos por marcadores moleculares RAPD e sugere que a segunda hipótese, talvez, explique a adaptabilidade do patógeno nas condições brasileiras.

U ma maior predominância de raças mais simples em relação a raças mais complexas foi verificada por Casela et al. (9), em estudo sobre a capacidade competitiva entre raças deste patógeno em misturas, indicando a possibilidade de influência da virulência na habilidade adaptativa de raças deste patógeno. Considerando-se que o acúmulo de virulência desnecessária resul ta em custo adaptativo para o patógeno (23), indi víduos com menor número de genes de virulência, equivalentes aos genes de resistência do hospedeiro, estariam mais aptos a predominar na população do patógeno.

De acordo com Costa (12), em populações hospedeiras mais complexas, há uma tendência à predominância de fenótipos mais complexos no patógeno. A pesar das raças de maior complexidade estarem em al ta freqüência, muitas raças de baixa complexidade também foram identificadas em todos os locais. Tal fato sugere que a seleção estabilizadora esteja atuando, em menor intensidade que a seleção direcional, contribuindo para a manutenção de um equilíbrio na população do patógeno, contra uma possível extinção dos fenótipos menos virulentos (16).

A alta freqüência de raças complexas identificadas neste trabal ho implica na ocorrência de associações positivas de virulência às linhagens utilizadas como diferenciadoras o que seria fator limitante para sua utilização em programas de mel horamento genético para a obtenção de resistência a este patógeno. Segundo Casela et al. (10), esta situação é observada com freqüência na população de $C$. sublineolum e é conseqüência da capacidade adaptativa do fungo, o que tem limitado 0 uso da resistência vertical para o manejo do patógeno.
M uitas raças estiveram presentes em mais de um local e é necessário buscar informações a respeito da origem de tais raças em cada população. Estas raças podem ter se originado a partir de uma pequena população que evoluiu em resposta a genótipos de sorgo comuns a cada região e também à ocorrência de fluxo gênico entre as populações. A ocorrência de fluxo gênico é provável, visto que o fungo pode ser transportado via sementes, como relatado por $\mathrm{C}$ ardwel et al. (5) e não há fiscalização sanitária entre regiões. Caso isto esteja ocorrendo, raças podem ser levadas de uma região para outra e favorecerem a "quebra" da resistência de cultivares em locais onde não estavam presentes anteriormente. A pesar de existir esta possibilidade, Rosewich et al. (20), utilizando marcadores RFLP em estudo da estrutura genética do patógeno, sugerem que o fluxo gênico e a deriva genética não foram os principais fatores a contribuir para a estrutura genética das populações anal isados, mas sim a reprodução assexuada. A utilização de marcadores moleculares pode auxiliar a obter informações sobre a origem de diferentes populações e ainda em determinar se a resistência será quebrada, quando associada a mudanças correspondentes na estrutura da população do patógeno.

Para diminuir os riscos de introdução de raças virulentas aos genes de resistência utilizados em determinada região, recomenda-se que apenas sementes sadias sejam transportadas entre regiões. Informações a respeito da população do patógeno presente em hospedeiras al ternativas, como Sorghum halepense e Sorghum verticilliflorum, no $B$ rasil, próximo às áreas de plantio, constitui-se também em um aspecto a ser considerado, para se avaliar a sua contribuição na geração e manutenção de uma maior diversidade na população do patógeno. Informações da diversidade populacional deste patógeno são importantes, portanto, para se prever, por meio da virulência a genótipos progenitores, quais cruzamentos poderiam gerar híbridos de alta resistência bem como para se definir estratégias que sejam eficientes no manejo da antracnose.

\section{AGRADECIMENTOS}

A o Conselho Nacional de Desenvolvimento Científico e Tecnológico pela concessão de bolsa de estudos para o curso de mestrado do primeiro autor.

À Fundação de A mparo à Pesquisa de M inas Gerais pelo financiamento do projeto de pesquisa.

À EM BRAPA M ilho e Sorgo pela concessão de espaço físico e recursos humanos durante a realização deste trabal ho.

\section{REFERÊNCIASBIBLIOGRÁFICAS}

1. A ndrivon, D.; De Vallavieille-Pope, C.R. Race diversity and complexity in selected populatins of fungal biotrophic pathogens of cereals. Phytopathology, St. Paul, v.85, p.897-905, 1995.

2. A lzate-M arin, A.L.; Cervigni, G.D.L.; M oreira, M.A.; B arros, E.G. Seleção assistida por marcadores moleculares visando ao desenvolvimento de plantas resistentes a doenças, com ênfase no feijoeiro e soja. Fitopatologia Brasileira, Brasília, v.30, n.4, p.333342, 2005.

3. Brown, J.K.M. Struture and evolution of a population of Erysiphe graminis f. sp. tritici. Plant Pathology, London, v.39, p.376-390, 1990.

4. Brown, J.K.M. Recombination and selection in population pathogens. Plant Pathology, London, v.44, p.279-293, 1995.

5. Cardwel, K.F.; Hepperly, P.R.; Frederikisen, R.A. Pathotipes of 
Colletotrichum graminicola and transmission of sorghum anthracnose. Plant Disease, St. Paul, v.73, p.255-257, 1989.

6. Casela, C.R. Investigations on the variability of the sorghum anthracnose fungus Colletotrichum graminicola. 1992. 166p. Dissertation (Ph. D.)-Texas A M University, Texas.

7. Casela, C.R.; Ferreira, A.S.; B rancao, N. Variabilidade e estrutura de virulência em Colletotrichum graminicola. Fitopatolologia Brasileira, Brasília, v,21, n.3, p.357-361, 1996.

8. Casela, C.R.; Ferreira, A.S.; Santos, F.G. A ssociação de virulência de Colletotrichum graminicola à resistência genética em sorgo. Fitopatologia Brasileira, Brasília, v.23, n.2, p.143-146, 1998.

9. Casela, C.R.; Ferreira, A.S.; Santos, F.G. Differences in competitive ability among races of Colletotrichum graminicola in mixtures. Fitopatologia Brasileira, Brasília, v.26, n.2, p.217-219, 2001.

10. Casela, C.R.; Ferreira, A.S.; Schaffert, R.E. Physiological races of Coletotrichum graminicola in Brazil. In: Milliano, W.A.J.; Frederiksen, R.A.; Bengstron, G.D. (Eds.). Sorghum and millets: a second world review. Pantacheru, A.P: India: International Crops Research Institute for Semi-A rid Tropics, 1992. p.209212.

11. Casela, C.R.; Santos, F.G.; Ferreira, A.S. Race diversity and complexity in populations of the sorghum anthracnose fungus Colletotrichum graminicola. Revista Brasileira de Milho e Sorgo, Sete Lagoas, v.3, n.1, p.30-37, 2004.

12. Costa, R.V. da. Estudo da herança e manejo da antracnose do sorgo por meio da diversificação da população hospedeira. 2004. 98f. Tese (Doutorado em Fitopatologia) - Universidade Federal de Viçosa, Viçosa.

13. Groth, J.V.; P.A, Roelfs. The concept and measurement of phenotypic diversity in Puccinia graminis on wheat. Phytopathology, St. Paul, v.77, n.10, p.395-1399, 1987.
14. Harris, H.B.; Jonhson, R. Sorghum anthracnose symptons, importance and resistance. In: Bien grain sorghum res. and util. conf., 5., 1967, Lubbock, Texas. Proceedings... Lubobock: Texas: Grain Sorghum Producers Assoc, 1967. p.48-52.

15. Kolmer, J.A. Phenotypic diversity in two populations of Puccinia recondita f. sp. tritici in Canada during 1931-1987. Phytopathology, St. Paul, v.81, n.3, p.311-315, 1991a.

16. Kolmer, J.A. Evolution of distinct populations of Puccinia recondita f. sp. tritici in Canada. Phytopathology, St. Paul, v.81, n.3, p.316-322, 1991b.

17. Mathur, $K$. et al. Sorghum anthracnose- problem and management strategies. In: Global 2000: sorghum and millet diseases 3. 2000, Guanajuato. Proceedings... Instomil: Sorghum and Millet International Research, 2003, p.1-27.

18. Nietsche, S. A.; et al. Genetic diversity of Phaeoisariopsis griseola in the State of Minas Gerais, Brazil. Euphytica, $N$ etherlands, v.117, p.77-84, 2001.

19. Pande, S. et al. Development of screening methods and identification of stable resistance to anthracnose in sorghum. Field Crops Research, St. Paul, v.38, p.157-166, 1994.

20. Rosewich, U.L. et al. Genetic structure and temporal dynamics of a Colletotrichum graminicola population in a sorghum disease nursery. Phytopathology, St. Paul, v.88, n.10, p.1087-1093, 1998.

21. Souza e Silva, F.A. Versão do programa computacional A ssistat para o sistema operacional Windows. Revista Brasileira de Produtos A groindustriais, Campina Grande, v.4, n.1, p.71-78, 2002.

22 Vanderplank, J.E. Host-pathogen interaction in plant disease. New York: A cademic, 1982, 207p.

23. Vanderplank, J.E. Disease resistance in plants. New York: A cademic, 1984. 194p. 